\title{
Treatment of a large maxillary cyst with marsupialization (case report)
}

\author{
Ahmed Fathi AL-Omar ${ }^{* *}$ and Khairy A Elmorsy ${ }^{2}$ \\ ${ }^{1}$ Department Of Oral and Maxillofacial Surgery, King Khalid University Hospital, Dental University Hospital, Faculty of Dentistry, King Saud University; Saudi Arabia \\ ${ }^{2}$ Oral and Maxillofacial Surgery, Cairo University, Egypt
}

\begin{abstract}
A large maxillary cyst was treated for 6 months with marsupialization and decompression, followed by surgical removal of the affected supernumerary teeth and cystectomy. Various treatment methods for huge cystic lesion of the jaw exist, such as, resection of the involved bone, enucleation and decompression. Among these methods, enucleation after decompression is a conservative technique that decreases the size of the cystic cavity and reduces the risk of intra-bony defects, which could be induced by primary enucleation. In addition, it can save the adjacent anatomic structures surgical enucleation of a large cystic lesion may lead to damage of other teeth or anatomic structures. Therefore, treatment should begin with the more conservative approach of decompression, to reduce the size of the lesion, followed by apicoectomy and cystectomy.
\end{abstract}

\section{Introduction}

Traumatic injuries to the teeth are relatively common, usually involving the anterior teeth of young patients. Such trauma is often followed by pulpal necrosis. If microbial infection occurs, a periapical lesion may develop, possibly evolving into a chronic inflammatory lesion (e.g., granuloma, periapical cyst or scar tissue). Periapical or radicular cysts are inflammatory jaw cysts affecting teeth with infected and necrotic pulp. These cysts occur as the direct sequelae of chronic apical periodontitis. Although the reported prevalence of cysts developing from apical periodontitis lesions varies from $6 \%$ to $55 \%$ [1]. Most radicular cysts develop slowly and do not become very large. Patients do not experience pain unless acute inflammatory exacerbation is present, and the lesions are often detected only during routine radiographic examination. If the cyst does become large, symptoms such as swelling, mild sensitivity, tooth mobility and displacement may be observed. The affected tooth is nonresponsive to thermal and electrical pulp tests [2]. The following case report describes the management of a particularly large maxillary cyst (involving 3 anterior teeth) by marsupialization with decompression. The technique of marsupialization, or Partsch's technique, consists of removing a window from the lesion and suturing the surrounding mucoperiosteum to the margins of the cyst wall. The ensuing cavity is filled with gauze, which is removed after seven to ten days. If necessary, the gauze is changed during this period. This technique has previously been described for surgical treatment of ranulas and is also used for treating bone cysts. This procedure aims to reduce the size of the cyst, opening the cyst eliminates its osmotic pressure and bone apposition gradually occurs at the site previously occupied by the epithelial covering of the cyst. These procedures can be used as a single treatment for a cyst or as preliminary treatment for subsequent enucleation [3].

Thomas [4] modified Partsch's method. In this modification, a small opening is made in the defect and a soft metal or polyethylene tube for drainage is inserted and fixed at the site by attaching it to an adjacent tooth. This technique was termed decompression.
Neaverth and Burg [5] presented an alternative treatment in which a tube was inserted inside the cystic cavity. This tube was periodically reduced in length as the lesion decreased in size. Several types and sizes of radiopaque tubes were used, such as: angiographic catheter, percutaneous catheter, urethral catheter and umbilical arterial catheter. All cases were in the maxilla. Full excision was not performed to avoid postoperative sequelae, such as devitalization of adjacent teeth, patient apprehension and discomfort, loss of bone support and paresthesia.

Kruger [6] presented a modified marsupialization technique. An acrylic button that can be crossed by a drill or a metal or plastic tube is used to keep the wound open, thereby allowing drainage and irrigation of the cystic cavity and keeping it clean. These devices are removed when radiographic examination shows that new bone has formed.

The indications for these procedures are as follows $[7,8]$ a) tissue damage - enucleation of a large cyst close to vital structures may cause damage such as oroantral or oronasal fistulas, devitalization of healthy teeth and nerve injuries (for example, of the inferior alveolar nerve); b) surgical access - when the access is very difficult, there may be recurrences; c) preservation of an impacted tooth - when an unerupted, impacted, permanent tooth is affected by, e.g., a dentigerous cyst, this procedure may guide the eruption; d) surgery extent - for debilitated, unhealthy or elderly patients, this is a less invasive and stressful procedure; e) cyst size - with very voluminous cysts, the risk of fracturing the mandible is always present. It may be better to first marsupialize or decompress the cyst, with subsequent enucleation once satisfactory bone neoformation has occurred.

Correspondence to: Ahmed Fathi AL-Omar, Assistant Consultant Department of Oral and Maxillofacial Surgery, King Khalid University Hospital, Dental University Hospital, Faculty of Dentistry, King Saud University, Saudi Arabia, E-mail: ahmed_ alomar@hotmail.com

Key words: maxillary cyst, marsupialization

Received: October 24, 2017; Accepted: November 29, 2017; Published: December 04, 2017 


\section{Case report}

A healthy 12-year-old male was referred from orthodontic clinic to the maxillofacial clinic of the faculty of dentistry of Cairo University (Egypt) for treatment of a large periapical lesion around the left maxillary central incisor. Orthopantomography (Figure 1) revealed a large periapical radiolucency, about $3 \mathrm{~cm}$ in the horizontal plane and $3 \mathrm{~cm}$ in the vertical plane, associated with teeth $21,22,23,24$ and possibly 25 and losing in central incisors. Clinical examination revealed labial swelling over these teeth, and facial asymmetry, and the area was tender to palpation and percussion. Teeth 22, 23 and 24 did not respond to thermal and electrical pulp tests. The provisional diagnosis was radicular cyst. Computed tomography (CT) revealed a lesion about $3 \mathrm{~cm}$ wide in the anteroposterior plane affecting the entire right premaxilla and contacting the floor of the nose and the maxillary sinus (Figure 2). Swelling, a buccal cortical break and expansion of the bone were obvious; these features indicated that the lesion was benign.

Cystectomy was considered, but the disadvantages of this treatment included the need to perform root canal treatment and apicoectomy of all affected teeth, possible damage to the floor of the nose or the maxillary sinus, and the need for general anesthesia. After consultation with the patient, his parents and various specialists, marsupialization with decompression was selected as an alternative approach. Specifically, the treatment plan called for decompression over a minimum of 12 weeks. Under general anesthesia incisional was performed in oral mucosa was removed from the site where the lesion-decompression gauze had been placed (Figure 3). The gauze was left in place for 15 days. The site was irrigated weekly with $0.2 \%$ chlorhexidine for six months, Lavage with sterile saline was performed, and a sample of the cystic capsule was taken for biopsy; histologic examination confirmed the diagnosis of inflammatory cyst.

After 6 months, radiographic examination revealed substantial healing (Figure 4). Specifically, trabecular bone was forming and the radiolucent area had diminished, as had the distances between the cyst and the nasal cavity and the maxillary sinus. However, healing was still incomplete.

After 6 months Clinical examinations showed no sensitivity to percussion or palpation, and the soft tissues were healthy. Clinical healing and radiographic resolution of the maxillary radiolucency were complete (Figure 5).

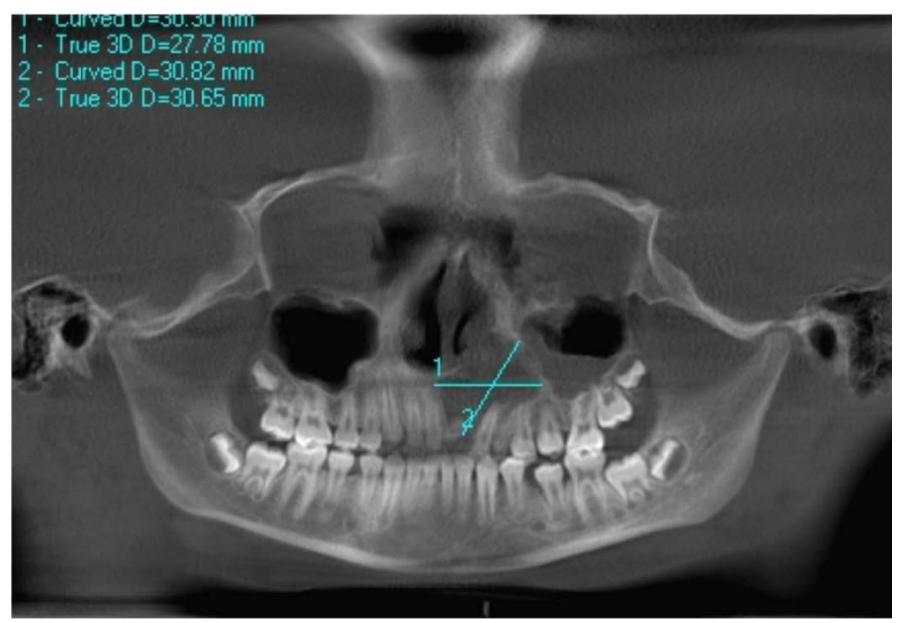

Figure 1. Panoramic view large periapical lesion around the left maxillary central incisor.

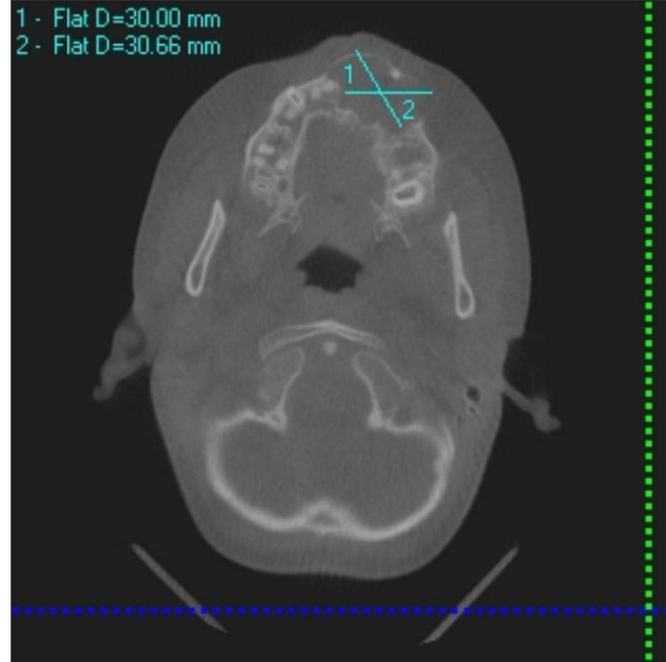

Figure 2. Computed tomography $(\mathrm{CT})$ revealed a lesion in the anteroposterior plane affecting the entire right premaxilla.

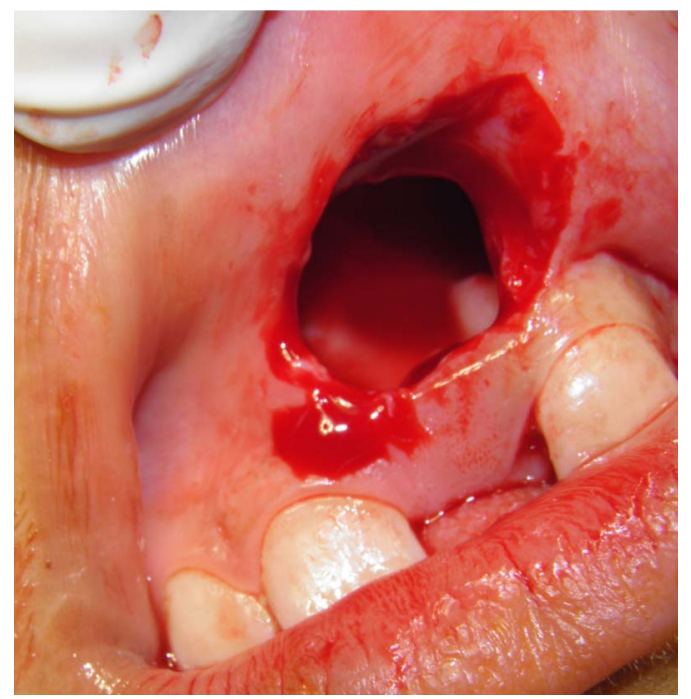

Figure 3. Incisional was performed in oral mucosa.

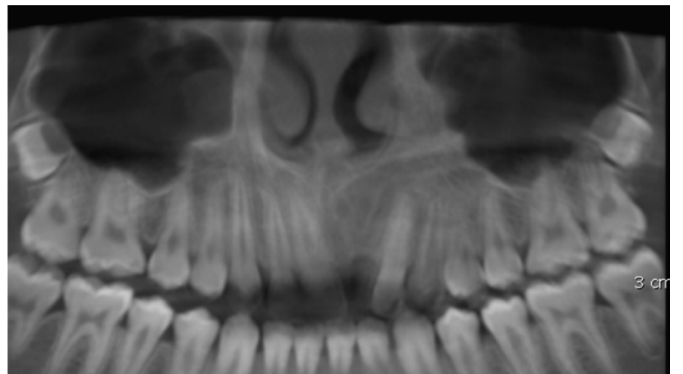

Figure 4. Panoramic view after 6 months, revealed trabecular bone was forming and the radiolucent area had diminished

\section{Discussion}

A wide variety of cysts and neoplasms may occur in the maxillofacial region, and their identification can be difficult. The most important of these are maxillary cysts [1]. A cyst is a pathological cavity with a defined wall of connective tissue and an epithelial carpet, filled with liquid, semiliquid or gaseous content. Growth of a cyst is typically slow, centrifugal and infiltrative [4]. Radicular cysts are thought to arise from 


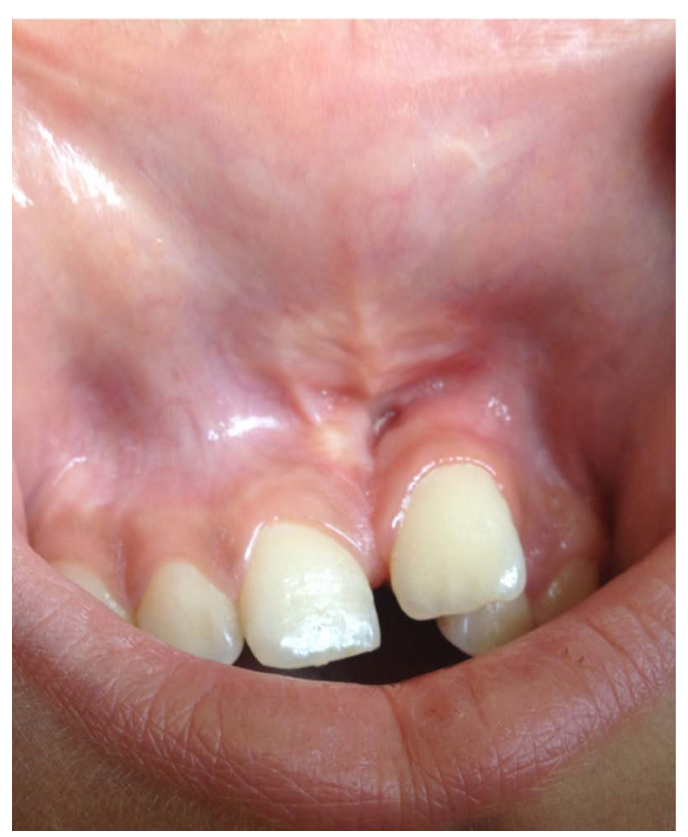

Figure 5. Clinical examinations showed the soft tissues were healthy.

epithelial cell rests of Malassez in the periodontal ligament, and they are believed to proliferate as a result of periapical inflammation caused by infection of the root canal system. They are particularly frequent in the maxillary anterior region, presumably as a result of trauma [9].

The management of large cystic lesions has been the subject of prolonged debate [10]. The treatment options for large periapical lesions range from conventional nonsurgical root canal treatment with long-term calcium hydroxide therapy to various surgical interventions. Some endodontists maintain that true cysts (those containing cavities completely enclosed by epithelial lining) can be successfully treated only by surgical means [11]. but the current endodontic philosophy for the treatment of large periapical lesions involves initial use of nonsurgical root canal treatment [12]. Therefore, patients should undergo clinical and radiological evaluation 6 months after the initial root canal treatment, to verify resolution of the lesion. However, a variety of scenarios may lead to the need for further surgical treatment of a lesion that presents greater compromise to the adjacent structures than was the case in the initial stages [10]. For example, the original diagnosis may have been incorrect, or the initial treatment may have been unsuccessful but the patient does not return until the situation has worsened and symptoms have reappeared. In this situation, additional options must be considered, such as nonsurgical retreatment or periapical surgery.

The usual surgical treatments for radicular cyst include total enucleation of small lesions, marsupialization for decompression of larger cysts or a combination of these techniques. Should surgical intervention become necessary, the clinician must decide whether to raise a flap and completely enucleate the lesion or to try "decompression" first $[12,13]$. If marsupialization with decompression is attempted first, the size of the lesion will be reduced, which will make it less difficult to remove, with less risk of damage to the associated teeth and vital structures [14]. For the case reported here, the surgical literature clearly indicated enucleation of the cyst as the preferred option, because marsupialization carries the risk that any cystic cells left behind may become malignant $[15,16]$. However, for this patient, it was felt that marsupialization was the best treatment option, thus avoiding the risk of damage to the floor of the nose or the maxillary sinus, and the need for general anesthesia.

Periapical cysts have an epithelial covering and expansive growth but still communicate with the root apex and could therefore be referred to as pseudocysts. A certain percentage of these pseudocysts become involuted with adequate canal treatment. In contrast, true periapical cysts have no communication with the root canal.

When the lesions are very extensive, as in the case reported here, the undesirable consequences of surgical curettage have led to the use of a tube decompression procedure, followed by apicoectomy and enucleation of the cyst. The marsupialization and decompression techniques are intended to reduce the size of the lesion [17]. However, they depend on the patient's cooperation, they take a long time, and they do not maintain the basic principles of endodontic therapy, especially with regard to preventing bacterial contamination throughout the oral environment. The percentage of radicular cysts that can be expected to heal with marsupialization and decompression alone is unknown, but this treatment modality bears consideration for the treatment of large cystic lesions [14].

The decompression technique has been proposed as an alternative to apical surgery for large areas of rarefaction involving anatomic structures [14]. However, we suggest that decompression be considered only as the first phase in treating large cystic lesions, with the intention of reducing the size of the lesion and facilitating subsequent surgical procedures.

Aldama [18] believed that the treatment for such cases should be radical and stated that the prognosis was good when the cystic capsule was fully removed. Kruger [6] warned that development cysts could undergo histological transformations. Therefore, specimens need to be carefully examined after surgery. Archer [8] advocated the technique of marsupialization in order to prevent the loss of the teeth involved, along with other complications that result in socalled dental mutilation. This author presented statistical data to support his argument: few benign or malignant tumors develop in cystic coverings that are thus maintained. The decompression technique is used prior to definitive excision in cases of large cysts. Olson et al. [19] reported excellent results regarding a case of a large odontogenic keratocyst when Partsch's technique was used, delaying enucleation. No recurrence was observed during a 4-year follow-up. Sverzut et al. [20] described a clinical case of mandibular dentigerous cyst. Treatment was done in two stages: firstly decompression and then enucleation 142 days later. Thirteen months later, the area was clinically and radiographically normal. Shear [21] believed that orthodontic care should always be available. However, Vieira et al. [22] presented the case of an eight-year-old patient who underwent marsupialization of the lesion and maintenance of the length of the dental arch. This allowed the associated permanent teeth to erupt without orthodontic traction. Neaverth and Burg [5] published four cases of decompression with plastic tubes in the anterior region of the maxilla, with excellent results. In these four cases, the tubes were removed after four weeks, five weeks, four months and one year. The present clinical case corroborates the findings of previous authors who believed in the viability of the procedure. Despite the unfavorable position of the incisor, decompression was done in hopes that the impacted permanent incisor would be able to assume its place in the dental arch. Once this decision was made, regular clinical and radiographic follow-ups were necessary because dentigerous cysts may turn into keratocysts. However, according to Branon [23], this is very unlikely. Pathological changes, such as degeneration to ameloblastomas, may occur and should be investigated in these cases by histopathology. 
In the case reported here, a steady decrease in the radiolucent area was apparent after 6 months of marsupialization and decompression, and cystectomy was performed easily and good stability in central incisor, Resolution of the lesion was complete after 8 months.

\section{References}

1. Nair PN, Sundqvist G, Sjögren U (2008) Experimental evidence supports the abscess theory of development of radicular cysts. Oral Surg Oral Med Oral Pathol Oral Radiol Endod 106: 294-303. [Crossref]

2. Lin LM, Ricucci D, Lin J, Rosenberg PA (2009) Nonsurgical root canal therapy of large cyst-like inflammatory periapical lesions and inflammatory apical cysts. $J$ Endod 35: 607-615. [Crossref]

3. Takase T, Wada M, Nagahama F, Yamazaki M (1996) Treatment of large radicular cysts by modified marsupialization. J Nihon Univ Sch Dent 38: 161-168. [Crossref]

4. THOMAS EH (1947) Cysts of the jaws; saving involved vital teeth by tube drainage. $J$ Oral Surg (Chic) 5: 1-9. [Crossref]

5. Neaverth EJ, Burg HA (1982) Decompression of large periapical cystic lesions. $J$ Endod 8: 175-182. [Crossref]

6. Kruger GO (1984) Cistos dos ossos, tecidos moles e estruturas adjacentes da cavidade bucal. In: Hupp JR, Ellis E, Myron R. Cirurgia bucal e maxilo facial. Rio de Janeiro: Guanabara Koogan 188-193.

7. Ellis E (1996) Tratamento cirúrgico das lesões orais patológicas. In: Peterson LJ. Cirurgia oral e maxilo facial contemporânea. Rio de Janeiro: Guanabara Koogan 467-490.

8. Archer W (1966) Oral surgery. 4th ed. Philadelphia: W.B. Saunders Co.1966

9. Lin LM, Huang GT, Rosenberg PA (2007) Proliferation of epithelial cell rests, formation of apical cysts, and regression of apical cysts after periapical wound healing. J Endod 33: 908-916.

10. Gallego Romero D, Torres Lagares D, García Calderón M, Romero Ruiz MM, Infante Cossio P, et al. (2002) Differential diagnosis and therapeutic approach to periapical cysts in daily dental practice. Med Oral 7: 54-62.
11. Nair PN, Sjögren U, Schumacher E, Sundqvist G (1993) Radicular cyst affecting a root-filled human tooth: a long-term post-treatment follow-up. Int Endod J 26: 225233. [Crossref]

12. Freedland JB (1970) Conservative reduction of large periapical lesions. Oral Surg Oral Med Oral Pathol 29: 455-464. [Crossref]

13. Neaverth EJ, Burg HA (1982) Decompression of large periapical cystic lesions. $J$ Endod 8: 175-182. [Crossref]

14. Martin SA (2007) Conventional endodontic therapy of upper central incisor combined with cyst decompression: a case report. J Endod 33: 753-757.

15. Gardner AF (1975) A survey of odontogenic cysts and their relationship to squamous cell carcinoma. Dent J 41: 161-167. [Crossref]

16. Schneider LC (1977) Incidence of epithelial atypia in radicular cysts: a preliminary investigation. J Oral Surg 35: 370-374. [Crossref]

17. Mejia JL, Donado JE, Basrani B (2004) Active nonsurgical decompression of large periapical lesions - 3 case reports. J Can Dent Assoc 70: 691-694.

18. Suárez Aldama J (1988) Dentigerous cyst. Report of an unusual case. Rev Cubana Estomatol 25: 81-85. [Crossref]

19. Olson RE, Thomsen S, Lin LM (1977) Odontogenic keratocyst treated by the Partsch operation and delayed enucleation: report of case. J Am Dent Assoc 94: 321-325. [Crossref]

20. Sverzut CE, Barros VMR, Brentegani LG, Gomes PP (2003) Descompressão e enucleação de cisto dentígero mandibular. Rev Assoc Paul Cir Dent 57: 299-302.

21. Shear M (1989) Cisto dentígero (folicular). In: Shear M. Cistos da região bucomaxilofacial. São Paulo: Santos 72-96.

22. Vieira AR, Modesto A, Soares VR (1995) Tratamento cirúrgico conservador de cisto dentígero. Rev Assoc Paul Cir Dent 49: 380-383.

23. Brannon RB (1976) The odontogenic keratocyst. A clinicopathologic study of 312 cases. Part I. Clinical features. Oral Surg Oral Med Oral Pathol 42: 54-72. [Crossref]

Copyright: (C2017 AL-OmarAF. This is an open-access article distributed under the terms of the Creative Commons Attribution License, which permits unrestricted use, distribution, and reproduction in any medium, provided the original author and source are credited. 